\title{
Suspected Female-to-Male Sexual Transmission of Zika Virus - New York City, 2016
}

\author{
Alexander Davidson, $\mathrm{MPH}^{1}$; Sally Slavinski, $\mathrm{DVM}^{1}$; Kendra Komoto ${ }^{1}$; Jennifer Rakeman, $\mathrm{PhD}^{1}$; Don Weiss, $\mathrm{MD}^{1}$
}

\begin{abstract}
On July 15, 2016, this report was posted as an MMWR Early Release on the MMWR website (http://www.cdc.gov/mmwr).
\end{abstract}

A routine investigation by the New York City (NYC) Department of Health and Mental Hygiene (DOHMH) identified a nonpregnant woman in her twenties who reported she had engaged in a single event of condomless vaginal intercourse with a male partner the day she returned to NYC (day 0) from travel to an area with ongoing Zika virus transmission. She had headache and abdominal cramping while in the airport awaiting return to NYC. The following day (day 1) she developed fever, fatigue, a maculopapular rash, myalgia, arthralgia, back pain, swelling of the extremities, and numbness and tingling in her hands and feet. In addition, on day 1, the woman began menses that she described as heavier than usual. On day 3 she visited her primary care provider who obtained blood and urine specimens. Zika virus RNA was detected in both serum and urine by real-time reverse transcription-polymerase chain reaction (rRT-PCR) performed at the DOHMH Public Health Laboratory using a test based on an assay developed at CDC (1). The results of serum testing for anti-Zika virus immunoglobulin $\mathrm{M}(\operatorname{IgM})$ antibody performed by the New York State Department of Health Wadsworth Center laboratory was negative using the CDC Zika IgM antibody capture enzyme-linked immunosorbent assay (Zika MAC-ELISA) (2).

Seven days after sexual intercourse (day 6), the woman's male partner, also in his twenties, developed fever, a maculopapular rash, joint pain, and conjunctivitis. On day 9, three days after the onset of his symptoms, the man sought care from the same primary care provider who had diagnosed Zika virus infection in his female partner. The provider suspected sexual transmission of Zika virus and contacted DOHMH to seek testing for the male partner. That same day, day 9, urine and serum specimens were collected from the man. Zika virus RNA was detected in urine but not serum by rRT-PCR testing at the DOHMH Public Health Laboratory. Zika virus IgM antibodies were not detectable by the CDC Zika MAC-ELISA assay performed at the New York State Department of Health Wadsworth Center. The CDC Arbovirus Disease Branch confirmed all rRT-PCR results for urine and serum specimens from both partners.

During an interview with DOHMH on day 17, the man confirmed that he had not traveled outside the United States during the year before his illness. He also confirmed a single encounter of condomless vaginal intercourse with his female partner (the patient) after her return to NYC and reported that he did not engage in oral or anal intercourse with her. The man reported that he noticed no blood on his uncircumcised penis immediately after intercourse that could have been associated either with vaginal bleeding or with any open lesions on his genitals. He also reported that he did not have any other recent sexual partners or receive a mosquito bite within the week preceding his illness.

Independent follow-up interviews with the woman and man corroborated the exposure and illness history. The patients were consistent in describing illness onset, symptoms, sexual history, and the woman's travel. This information also was consistent with the initial report from the primary care provider.

The timing and sequence of events support female-to-male Zika virus transmission through condomless vaginal intercourse. The woman likely was viremic at the time of sexual intercourse because her serum, collected 3 days later, had evidence of Zika virus RNA by rRT-PCR. Virus present in either vaginal fluids or menstrual blood might have been transmitted during exposure to her male partner's urethral mucosa or undetected abrasions on his penis. Recent reports document detection of Zika virus in the female genital tract, including vaginal fluid. A study on nonhuman primates found Zika virus RNA detected in the vaginal fluid of three nonpregnant females up to 7 days after subcutaneous inoculation (3), and Zika virus RNA was detected in specimens from a woman's cervical mucous, genital swab, and endocervical swab collected 3 days after illness onset, using an unspecified RT-PCR test (4). Further studies are needed to determine the characteristics of Zika virus shedding in the genital tract and vaginal fluid of humans.

This case represents the first reported occurrence of femaleto-male sexual transmission of Zika virus. Current guidance to prevent sexual transmission of Zika virus is based on the assumption that transmission occurs from a male partner to a receptive partner $(5,6)$. Ongoing surveillance is needed to determine the risk for transmission of Zika virus infection from a female to her sexual partners. Providers should report to their local or state health department any patients with illnesses compatible with Zika virus disease who do not have a history 
of travel to an area with ongoing Zika virus transmission, but who had a sexual exposure to a partner who did travel.

Persons who want to reduce the risk for sexual transmission of Zika virus should abstain from sex or correctly and consistently use condoms for vaginal, anal, and oral sex, as recommended in the current CDC guidance (5). Guidance on prevention of sexual transmission of Zika virus, including other methods of barrier protection, will be updated as additional information becomes available (http://www.cdc.gov/zika).

\footnotetext{
${ }^{1}$ New York City Department of Health and Mental Hygiene, New York.

Corresponding author: Sally Slavinski, sslavins@health.nyc.gov, 347-396-2672.
}

\section{References}

1. Lanciotti RS, Kosoy OL, Laven JJ, et al. Genetic and serologic properties of Zika virus associated with an epidemic, Yap State, Micronesia, 2007. Emerg Infect Dis 2008;14:1232-9. http://dx.doi.org/10.3201/ eid1408.080287

2. CDC. Zika MAC-ELISA: instructions for use. Atlanta, GA: US Department of Health and Human Services, CDC; 2016. http://www. fda.gov/downloads/MedicalDevices/Safety/EmergencySituations/ UCM488044.pdf

3. Dudley DM, Aliota MT, Mohr EL, et al. A rhesus macaque model of Asian-lineage Zika virus infection. Nat Commun 2016;7:12204. http:// dx.doi.org/10.1038/ncomms 12204

4. Prisant N, Bujan L, Benichou H, et al. Zika virus in the female genital tract [Letter]. Lancet Infect Dis 2016. E-pub July 11, 2016. http://dx.doi. org/10.1016/S1473-3099(16)30193-1

5. Oster AM, Russell K, Stryker JE, et al. Update: interim guidance for prevention of sexual transmission of Zika virus-United States, 2016. MMWR Morb Mortal Wkly Rep 2016;65:323-5. http://dx.doi. org/10.15585/mmwr.mm6512e3

6. Hills SL, Russell K, Hennessey M, et al. Transmission of Zika virus through sexual contact with travelers to areas of ongoing transmission - continental United States, 2016. MMWR Morb Mortal Wkly Rep 2016;65:215-6. http://dx.doi.org/10.15585/mmwr.mm6508e2 